\author{
Andrzej GRZEBIELEC ${ }^{1}$ \\ Artur RUSOWICZ ${ }^{2}$
}

\title{
WYKORZYSTANIE GRUNTOWYCH POMP CIEPŁA W SYSTEMACH KLIMATYZACJI
}

\begin{abstract}
Pompy ciepła, współpracujące z gruntowymi wymiennikami ciepła są urządzeniami charakteryzującymi się jednymi z wyższych współczynników efektywności wśród pomp ciepła. Lepsze efekty udaje się osiągnąć jedynie w przypadku urządzeń współpracujących z wodą gruntową. Najgorsze, z punktu widzenia efektywności energetycznej są rozwiązania wykorzystujące powietrze atmosferyczne jako dolne źródło ciepła. Nie mniej jednak, z punktu widzenia ekonomii daleko im do rozwiązań z kotłami węglowymi czy nawet gazowymi. Głównym problemem są koszty inwestycyjne. W przypadku instalacji z pompami ciepła koszty inwestycyjne są od kilku do kilkunastu razy wyższe. Celem pracy jest określenie, w jaki sposób można poprawić ekonomiczny aspekt pracy pomp ciepła poprzez wykorzystanie ich w systemach klimatyzacji w okresie letnim. W celu modelowania pracy układu został wykorzystany model ASHRAE dla wymienników gruntowych pionowych dla polskich warunków atmosferycznych. Wyniki pracy pokazują, że istniejącą instalację z pompą ciepła można wykorzystać do celów klimatyzacyjnych, a dodatkowo, w znaczący sposób można poprawić efektywność pracy układów klimatyzacji (25\%). Wynika to z faktu, że w tego typu rozwiązaniach górnym źródłem ciepła, w systemach klimatyzacji jest grunt a nie powietrze atmosferyczne. Grunt w okresie letnim charakteryzuje się niższą temperaturą niż powietrze atmosferyczne. Wszystkie te czynniki powodują, że bilans ekonomiczny instalacji z pompą ciepła robi się coraz bardziej korzystny. Jednak, aby osiągnąć jak najlepsze rozwiązanie, należy współpracę systemu grzewczego z systemem klimatyzacji uwzględnić już na poziomie projektowania budynku.
\end{abstract}

Słowa kluczowe: pompy ciepła, wymienniki gruntowe, klimatyzacja, efektywność energetyczna, modelowanie matematyczne

\section{Wprowadzenie}

Pompy ciepła są urządzeniami grzewczymi wykorzystywanymi do ogrzewania budynków, ale także wykorzystywanymi w innych procesach na przykład w suszarnictwie [5]. Można spotkać także hybrydy łączące w sobie pompy cie-

\footnotetext{
${ }^{1}$ Autor do korespondencji: Andrzej Grzebielec, Politechnika Warszawska, Instytut Techniki Cieplnej, 00-665 Warszawa, ul. Nowowiejska 21/25, +48 22234 52 32, angrzeb@itc.pw.edu.pl ${ }^{2}$ Artur Rusowicz, Politechnika Warszawska, Instytut Techniki Cieplnej, 00-665 Warszawa, ul. Nowowiejska 21/25, +48 2223452 21, rusowicz@itc.pw.edu.pl
} 
pła i kolektory słoneczne [2]. Pompy ciepła realizują obiegi lewobieżne. Obiegi lewobieżne są realizowane także przez układy klimatyzacji czy chłodniczomroźnicze [8]. Ich zadaniem jest transportowanie ciepła ze środowiska o temperaturze niższej do środowiska o temperaturze wyższej. Urządzenia te, wykorzystują najczęściej energię mechaniczną (z technicznego punktu widzenia są to sprężarki). Warto wspomnieć, że w technice można spotkać także inne sposoby realizacji obiegów lewobieżnych, są to pompy ciepła: absorpcyjne, adsorpcyjne, termoelektryczne, termoakustyczne czy magnetyczne [5]. W chwili obecnej to właśnie urządzenia sprężarkowe są najczęściej spotykane. Wynika to z dwóch faktów: ceny urządzenia oraz wysokich współczynników efektywności tego typu rozwiązania w porównaniu $\mathrm{z}$ innymi pompami ciepła.

Uwzględniając koszty inwestycyjne i eksploatacyjne, pompom ciepła nadal daleko do rozwiązań, w których stosuje się kotły węglowe czy gazowe. Analizy ekonomiczne pokazują, że czas zwrotu inwestycji w pompę ciepła to okres kilkudziesięciu lat. Trzeba pamiętać, że najdłużej, co 20 lat, instalację trzeba wymieniać na zupełnie nową. Tak więc inwestycja jest nieopłacalna.

Pompy ciepła w porównaniu z kotłami mają jednak zaletę, można je wykorzystać do celów klimatyzacyjnych. A komfort cieplny coraz bardziej staje się istotny dla Polaków w okresie wiosenno, letnio, jesiennym. I systemy klimatyzacji stają się coraz bardziej popularne i to nie tylko w budynkach użyteczności publicznej czy biurowcach, ale także w budownictwie mieszkaniowym. Kotły także da się wykorzystać w systemach klimatyzacji realizując obiegi adsorpcyjne, absorpcyjne czy termoakustyczne jednak ich efektywność jest kilka razy niższa niż układów sprężarkowych, co sprawia, że ekonomicznie jest to nieopłacalne.

Rozwiązania stosowane w budynkach użyteczności publicznej czy biurowcach są powszechnie znane, poza tym $\mathrm{w}$ ich działaniu często priorytetem nie jest ekonomia tylko komfort cieplny. Dlatego w artykule skupiono się na rozwiązaniach dedykowanych dla budownictwa mieszkaniowego - głównie domków jednorodzinnych.

\section{Metody wykorzystania pomp ciepła w systemach klimatyzacji}

Obecnie dostępne na rynku pompy ciepła zazwyczaj wyposażone są w zawór czterodrogowy, który umożliwia zmianę kierunku transportu ciepła. Zimą ciepło transportowane jest $\mathrm{z}$ gruntu do budynku, latem ciepło transportowane jest $\mathrm{z}$ budynku do gruntu. Fizycznie realizowane jest to w ten sposób, że parownik ze skraplaczem zmieniają swoje role.

Pompy ciepła można zintegrować z systemami klimatyzacji na kilka sposobów. Zależy to od systemu klimatyzacji, sposobu ogrzewania budynku, a także od momentu, w którym następuje integracja obu systemów. Najlepszym momentem jest integracja na poziomie projektowania budynku oraz obu systemów. Jednak najczęstsza praktyka jest taka, że integracja następuje w późniejszej fazie poprzez dołożenie systemu klimatyzacji do istniejącego systemu ogrzewania. 


\subsection{Układy klimatyzacji pośredniej}

Układy pośrednie charakteryzują się tym, że powietrze znajdujące się $\mathrm{w}$ pomieszczeniach chłodzone jest $\mathrm{z}$ wykorzystaniem czynnika pośredniczącego. Najczęściej tym czynnikiem jest woda, gdyż układy te pracują w zakresie temperatury od $+7 \mathrm{do}+12{ }^{\circ} \mathrm{C}$. Coraz bardziej popularne są rozwiązania $\mathrm{z}$ wykorzystaniem materiałów PCM, które umożliwiają magazynowanie pewnej ilości ciepła (chłodu) [3,9]. Wśród tych systemów można wyróżnić dwa rodzaje rozwiązań. Tak zwaną klimatyzację podłogową (rysunek nr 1), jak i klimatyzację wykorzystującą wymienniki naścienne czy klimakonwektory.

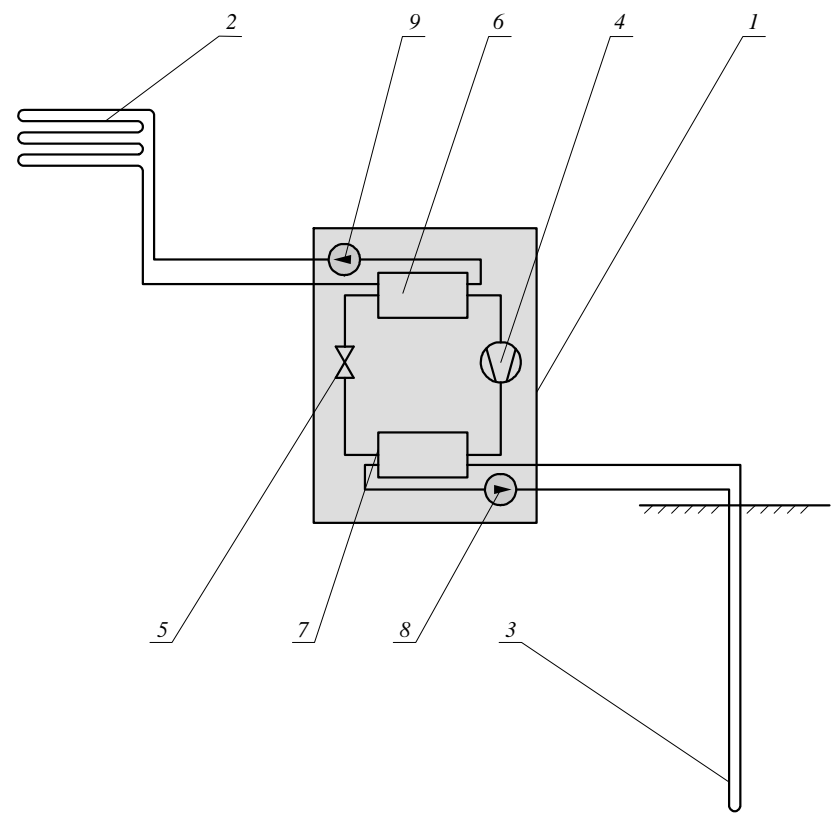

Rys. 1. Pompa ciepła wykorzystywana do chłodzenia podłogowego (1 - pompa ciepła, 2 - wymiennik podłogowy, 3 - pionowy wymiennik gruntowy, 4 - sprężarka, 5 - zawór rozprężny, 6 - wymiennik pełniący rolę parownika, 7 - wymiennik pełniący rolę skraplacza, 8 - pompa obiegowa wodnego roztworu glikolu, 9 - pompa obiegowa wody lodowej)

Fig. 1. The heat pump used for floor cooling systems (1 - heat pump, 2 - floor heat exchanger, 3 - vertical ground heat exchanger, 4 - compressor, 5 - expansion valve, 6 - evaporator, 7 - condenser, 8 - glycol punp, 9 - chilled water circulation pump)

Pomimo wielu wad, chłodzenie podłogowe jest najczęściej spotykane w tego typu układach klimatyzacji pośredniej, gdyż uruchomienie tego typu klimatyzacji to tylko zmiana trybu pracy pompy ciepła, wykorzystującej zasadę działania zaworu czterodrogowego. Oznacza to, że każdy kto posiada pompę ciepła przeznaczoną do ogrzewania podłogowego, automatycznie posiada także 
możliwość wykorzystania jej do klimatyzacji podłogowej. Ograniczeniem jest tutaj jedynie sposób integracji pompy ciepła z systemem ciepłej wody użytkowej. Rozwiązanie to posiada dwie główne wady. Pierwsza z nich to efekt tak zwanej zimnej podłogi. Ludzie generalnie preferują ciepłą podłogę a chłodniejsze powietrze na wysokości głowy. Druga wada to możliwość wykraplania się pary wodnej na powierzchni podłogi. Stosując klimakonwektory istnieje możliwość odprowadzania skroplin i unika się zimnej podłogi.

\subsection{Układy klimatyzacji bezpośredniej}

Klimatyzacja bezpośrednia musi być przewidziana na poziomie projektu, gdyż czynnik roboczy pomp ciepła dopływa bezpośrednio do wymienników ciepła znajdujących się w poszczególnych pomieszczeniach, gdzie przez zmianę fazy realizuje proces grzania lub chłodzenia powietrza. Na schemacie (rys. 2) została zaprezentowana pompa ciepła zintegrowana $\mathrm{z}$ tego typu systemem. W każdym pomieszczeniu, które należy ogrzewać czy chłodzić musi znajdować się co najmniej jeden wymiennik ciepła. Rozwiązania te są generalnie kojarzone z układami klimatyzacji o nazwach $\mathrm{VRV}^{3}$ czy $\mathrm{VRF}^{4}$, co na język polski tłumaczy się jako układy ze zmiennym przepływem czynnika chłodniczego. Układy te charakteryzują się wysokimi współczynnikami efektywności zarówno chłodniczej jak i grzewczej natomiast posiadają kilka wad. Układy są rozległe co powoduje, że ewentualne nieszczelności są trudne do wykrycia. Ze względu na zmienny przepływ czynnika roboczego w układach pojawiają się problemy ze smarowaniem sprężarki, gdyż olej nie zawsze krąży w sposób optymalny. Układy ze zmiennym przepływem czynnika roboczego występują w dwóch typach: dwururowe i trójrurowe. Na schemacie (rys. 2) został pokazany układ dwururowy co powoduje, że cała instalacja pracuje albo jako pompa ciepła albo jako układ klimatyzacji. W układach trójrurowych istnieje możliwość, ustawiania trybu pracy dla każdego wymiennika. Takie rozwiązanie jest szczególnie przydatne dla budynków mocno przeszklonych, gdzie w okresie wiosennym czy jesiennym południowe strony trzeba ochładzać, a północne ogrzewać.

Innym rozwiązaniem klimatyzacji bezpośredniej jest wykorzystanie pompy ciepła w systemach z wentylacją kanałową (rysunek 3). Legislacja Unii Europejskiej przewiduje, że za kilka lat wszystkie nowo powstające domy muszą charakteryzować się bardzo niskimi współczynnikami zużycia energii. Ograniczanie przewodności cieplnej przegród budowlanych jest faktem i już w chwili obecnej większość strat ciepła z budynku to straty wentylacyjne. W celu obniżenia strat wentylacyjnych przewidywane jest, że wszystkie budynki będą wyposażone w systemy wentylacji mechanicznej oraz w rekuperatory.

\footnotetext{
${ }^{3}$ VRV - Variable Refrigerant Volume - zmienna objętość przepływającego czynnika chłodniczego

${ }^{4}$ VRF - Variable Refrigerant Flow - zmienny przepływ czynnika chłodniczego
} 


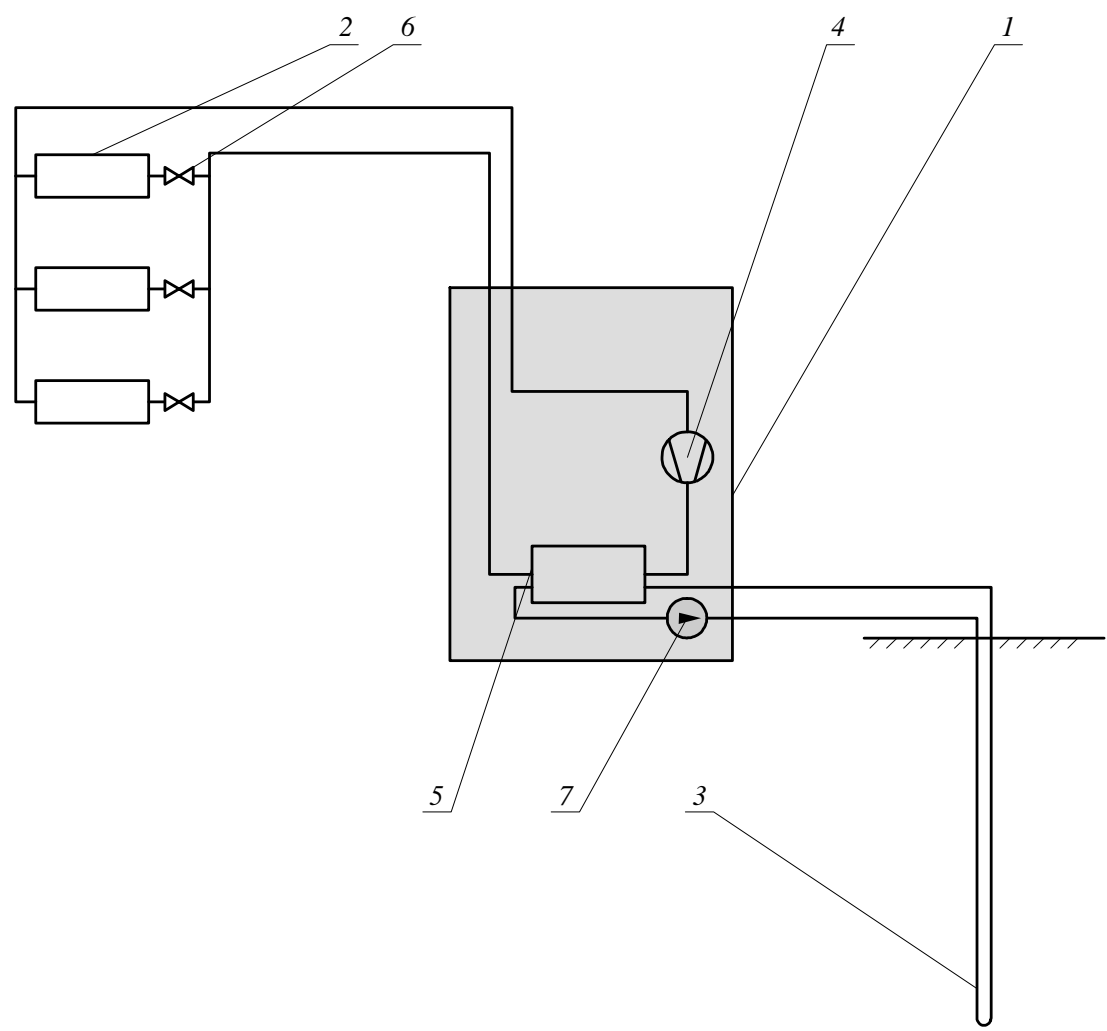

Rys. 2. Pompa ciepła wykorzystywana w układach bezpośredniego odparowania (1 - pompa ciepła, 2 - parownik układu sprężarkowego, 3 - pionowy wymiennik gruntowy, 4 - sprężarka, 5 - wymiennik pełniący rolę skraplacza, 6 - zawór rozprężny, 7 - pompa obiegowa wodnego roztworu glikolu)

Fig. 2. The heat pump used in direct expansion systems (1 - heat pump, 2 - evaporators, 3 - vertical ground heat exchanger, 4 - compressor, 5 - condenser, 6 -, expansion valve, 7 - glycol pump)

Powszechne wykorzystanie rekuperatorów spowoduje, że budynki będą wyposażone w kanałowy system dostarczania świeżego powietrza do budynku. Jeżeli w budynku znajduje się kanałowa wentylacja mechaniczna z powodzeniem można ją wykorzystać do celów grzewczych jak i klimatyzacyjnych. W głównym kanale należy umieścić wymiennik pompy ciepła. Podobnie jak w poprzednim wypadku system ten musi być przewidziany $\mathrm{w}$ momencie projektowania budynku, gdyż do istniejącego systemu wentylacji mechanicznej najczęściej nie będzie można dołożyć wymienników. Jeśli system wentylacji przewidziany jest tylko do dostarczania świeżego powietrza, to strumień powietrza będzie niewystarczający aby przenieść także wymaganą ilość ciepła. W tym celu system wentylacji musi być wyposażony w komorę mieszania, a część powietrza musi być zawracana. 


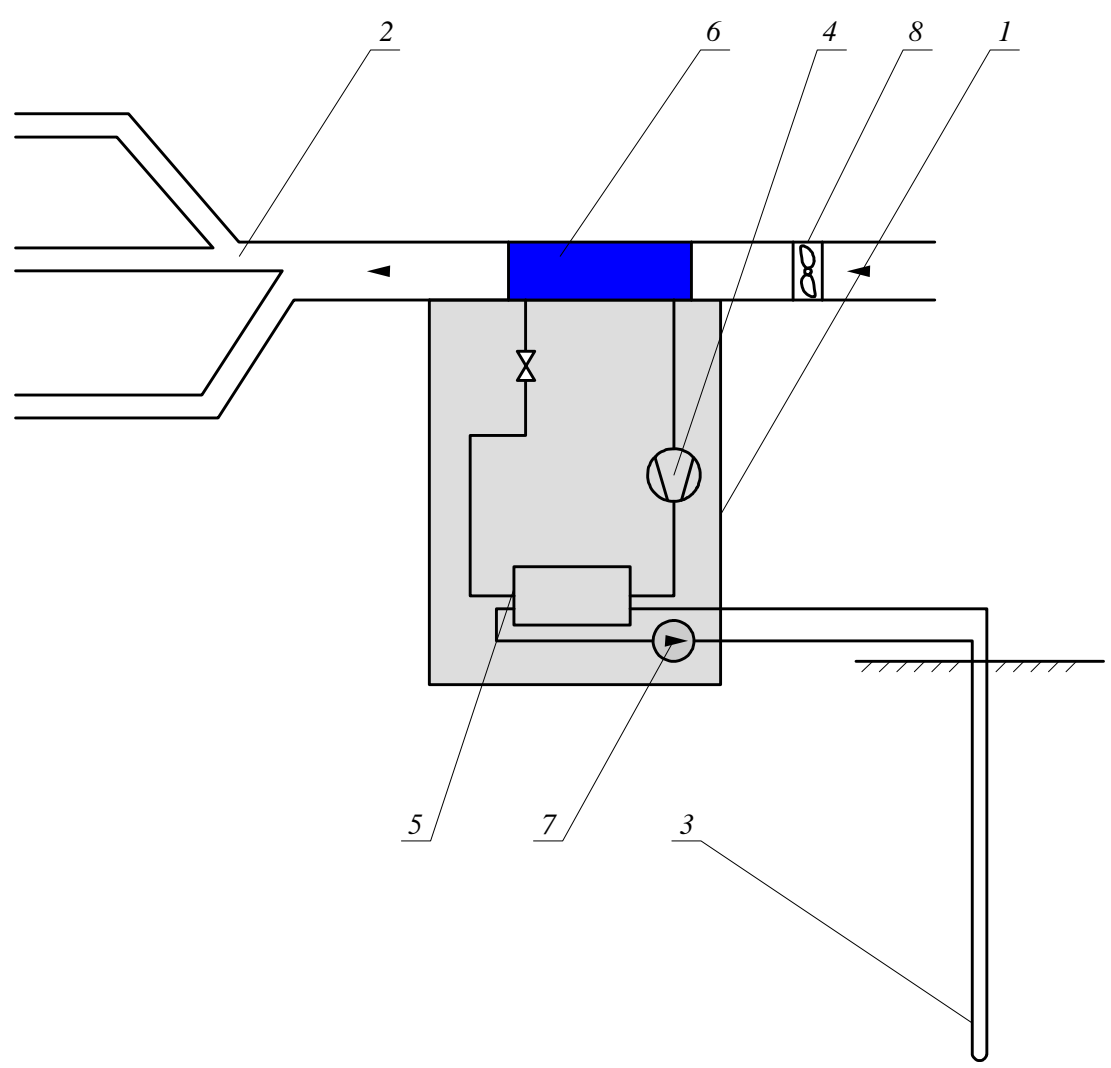

Rys. 3. Pompa ciepła współpracująca z kanałowym systemem chłodzenia (1 - pompa ciepła, 2 - system kanałów wentylacyjnych, 3 - pionowy wymiennik gruntowy, 4 - sprężarka, 5 - wymiennik pełniący rolę skraplacza, 6 - kanałowy parownik, 7 pompa obiegowa wodnego roztworu glikolu, 8 - wentylator)

Fig. 3. The heat pump works with ventilation system (1 - heat pump, 2 - air ducts, 3 - vertical ground heat exchanger, 4 - compressor, 5 - condenser, 6 - evaporator, 7 - glycol pump, 8 - fan)

\section{Metodologia badań}

Ze względu na fakt, że budynki będą coraz bardziej energooszczędne, rozwiązaniem, które będzie najbardziej popularne, to układ składający się z pompy ciepła z wymiennikami gruntowymi pionowymi, wentylacją mechaniczną kanałową, wyposażoną $\mathrm{w}$ rekuperator. $\mathrm{Z}$ tego powodu modelowaniu matematycznemu zostanie poddany obiekt zbudowany właśnie w takiej konfiguracji. Układ został przedstawiony na schemacie (rys. 3). W przypadku zastosowania układu wentylacji do dostarczania lub odbierania ciepła do/z pomieszczeń kanały muszą być większe niż w przypadku stosowania ich jedynie do dostarczania wymaganej ilości świeżego powietrza. Jednak niewątpliwą zaletą tego rozwiązania 
jest fakt, że pompa ciepła będzie pracować ze zdecydowanie lepszymi współczynnikami efektywności niż w przypadku ogrzewania podłogowego. Jest to spowodowane niższą temperaturą górnego źródła ciepła. Powietrze należy ogrzewać do temperatury około $22^{\circ} \mathrm{C}$, a w przypadku wody płynącej w grzejnikach podłogowych czy klimakonwektorach należy ją podgrzać do co najmniej $40^{\circ} \mathrm{C}$. Podobnie sytuacja ma się $\mathrm{w}$ przypadku klimatyzacji. Powietrze należy ochłodzić do $25^{\circ} \mathrm{C}$, a w przypadku układów pośrednich, wodę lodową standardowo schładza się do $7^{\circ} \mathrm{C}$.

Czynnik roboczy, jaki zostanie zastosowany w układzie pompy ciepła, to czynnik R407C, jeden z popularniejszych w chwili obecnej czynników roboczych stosowanych w sprężarkowych pompach ciepła [6].

\section{Model obliczeniowy}

Do obliczeń został przystosowany model proponowany przez ASHRAE [1], w którym wyznacza się, jak głęboki powinien być odwiert w przypadku gdy pompa ciepła jest wykorzystywana do celów grzewczych (równanie 1) oraz jak głęboki powinien być odwiert w przypadku, gdy pompę ciepła wykorzystuje się do celów klimatyzacji (równanie 2).

$$
\begin{aligned}
& L_{h}=\frac{q_{a} R_{g a}+\left(q_{l h}-W_{h}\right)\left(R_{p}+P L F_{m} R_{g m}+R_{g d} F_{s c}\right)}{t_{g}-\frac{t_{w i}+t_{w o}}{2}-t_{p}} \\
& L_{c}=\frac{q_{a} R_{g a}+\left(q_{l c}-W_{c}\right)\left(R_{p}+P L F_{m} R_{g m}+R_{g d} F_{s c}\right)}{t_{g}-\frac{t_{w i}+t_{w o}}{2}-t_{p}}
\end{aligned}
$$

gdzie:

$\mathrm{F}_{\mathrm{sc}}$ - współczynnik strat cieplnych wynikających z przekazywania ciepła z rurki do rurki (w jednej roztwór glikolu płynie w dół, w drugiej do góry),

$\mathrm{L}_{\mathrm{c}}$ - wymagana długość odwiertu dla układu klimatyzacji,

$\mathrm{L}_{\mathrm{h}}$ - wymagana długość odwiertu dla układów ogrzewania grzania,

$\mathrm{PLF}_{\mathrm{m}}$ - współczynnik określający ile miesięcznie pompa ciepła będzie pracować, 0 - oznacza, że nie będzie wcale pracować, 1 - że przez $100 \%$ czasu będzie włączona,

$\mathrm{q}_{\mathrm{a}}$ - średni roczny strumień ciepła dostarczanego do gruntu (uwzględniający pracę pompy ciepła, zarówno jako urządzenie grzejne jak i klimatyzacyjne),

$\mathrm{q}_{\mathrm{lc}}$ - zapotrzebowanie budynku na chłód w kW,

$\mathrm{q}_{\mathrm{lh}}$ - obliczeniowe zapotrzebowanie budynku na ciepło $\mathrm{w} \mathrm{kW}$,

$\mathrm{R}_{\mathrm{ga}}-$ efektywny opór cieplny gruntu dla impulsu rocznego, $(\mathrm{m} \cdot \mathrm{K}) / \mathrm{kW}$; 
$\mathrm{R}_{\mathrm{gd}}$ - efektywny opór cieplny gruntu dla impulsu dziennego, $(\mathrm{m} \cdot \mathrm{K}) / \mathrm{kW}$;

$\mathrm{R}_{\mathrm{gm}}$ - efektywny opór cieplny gruntu dla impulsu miesięcznego, $(\mathrm{m} \cdot \mathrm{K}) / \mathrm{kW}$;

$\mathrm{R}_{\mathrm{p}}$ - opór cieplny przewodzenia przez rurkę;

$\mathrm{t}_{\mathrm{g}}-$ niezmienna średnia roczna temperatura gruntu, ${ }^{\circ} \mathrm{C}$;

$t_{p}$ - temperatura obniżenia/podniesienia niezmiennej temperatury gruntu, wywo-

łana odwiertami w pobliżu modelowanego odwiertu.

$\mathrm{t}_{\mathrm{wi}}$ - temperatura cieczy przy wlocie do wymiennika pompy ciepła;

$\mathrm{t}_{\mathrm{wo}}$ - temperatura cieczy przy wylocie $\mathrm{z}$ wymiennika pompy ciepła;

$\mathrm{W}_{\mathrm{c}}$ - moc elektryczna pompy ciepła podczas chłodzenia;

$\mathrm{W}_{\mathrm{h}}$ - moc elektryczna pompy ciepła podczas grzania;

Projektując układ jednocześnie przeznaczony do grzania oraz chłodzenia, należy wybrać dłuższy z odwiertów. Stosując metod różnic skończonych wyznaczone zostały godzinowe parametry glikolu wpływającego i wypływającego z wymiennika. Na podstawie tej wartości określona została temperatura przemiany fazowej czynnika R407C w wymienniku pompy ciepła. Analogiczne obliczenia dla systemu wentylacyjnego oraz danych meteorologicznych [12] pozwoliły wyznaczyć temperaturę przemiany fazowej w drugim wymienniku pompy ciepła. Na podstawie temperatur została wyznaczona godzinowa efektywność pompy ciepła. W ten sposób uzyskano efektywność układu dla każdej godziny w roku.

\section{Wyniki obliczeń}

Na podstawie obliczeń zostało określone jaki wpływ na system klimatyzacji ma wykorzystanie pompy ciepła współpracującej z wymiennikiem gruntowym. Dla modelowanego budynku pracującego z klimatyzacją ze skraplaczami chłodzonymi przez powietrze zewnętrze z czynnikiem roboczym R407C, średnioroczny współczynnik efektywności chłodniczej wyniósł 3,38. Natomiast wykorzystując pompę ciepła współczynnik efektywności wzrósł do 4,5. Wynika to $\mathrm{z}$ faktu, że temperatura skraplania $\mathrm{w}$ tym drugim przypadku była niższa o $10 \mathrm{~K}$. W praktyce oznacza to, że eksploatacyjne koszty użytkowania zmniejszą się także o $25 \%$, co w przypadku systemów klimatyzacji jest bardzo dużym osiągnięciem. Oprócz wpływu działania pompy ciepła na system klimatyzacji, system klimatyzacji korzystnie wpłynie na system grzania. To z kolei wynika z faktu, że podczas sezonu letniego, kiedy układ odbiera ciepło z powietrza $\mathrm{i}$ transportuje je do gruntu - ciepło to jest następnie zimą odbierane. Oznacza to, że w okresie zimowym temperatura gruntu będzie wyższa niż w systemie, w którym układu klimatyzacji nie ma. Powoduje to, że temperatura parowania czynnika roboczego będzie wyższa, a to z kolei powoduje, że średnioroczny współczynnik efektywności pompy ciepła także będzie wyższy. Z obliczeń wynika, że zyski te będą rzędu $11 \%$. 


\section{Podsumowanie}

Komfort zarówno cieplny jak i ten rozumiany ogólnie, ma coraz większe znaczenie dla ludzi mieszkających w Polsce. $\mathrm{Z}$ tego też powodu układy klimatyzacji stają się coraz popularniejsze. Praca pokazuje, że posiadając pompę ciepła w budynku można w znaczący sposób obniżyć koszty użytkowania systemów klimatyzacji. Standardowe systemy klimatyzacji charakteryzować się mogą średnio o 1 niższym współczynnikiem sezonowym COP. Wg obliczeń różnica ta wynosi 1,12 . Wynika to $\mathrm{z}$ kilku przyczyn. Temperatura górnego źródła ciepła jest niższa niż w przypadku klimatyzacji standardowej, a to powoduje, że układ będzie pracował z wyższą efektywnością. Z drugiej strony układ klimatyzacji poprawia działanie systemu grzewczego zimą, gdyż grunt wokół wymienników w pewnym sensie będzie działał jak magazyn ciepła. To sprawi, że sezon grzewczy będzie się rozpoczynał ze zdecydowanie wyższą temperaturą gruntu niż w przypadku układu niewspółpracującego z system klimatyzacji. Z obliczeń wynika, że efektywność pompy ciepła wzrośnie o $11 \%$.

\section{Literatura}

[1] ASHRAE Handbook, 1999 HVAC Applications, A31 Geotermal energy.

[2] Chabane f., Moummi N., Benramache S.: Experimental analysis on thermal performance of a solar air collector with longitudinal fins in a region of Biskra, Algeria. Journal of Power Technologies 93 (1) (2013) 52-58.

[3] Chwieduk D.: Dynamics of external wall structures with a PCM (phase change materials) in high latitude countries. Energy 59 (2013) pp. 301-313.

[4] Cyklis P., Kantor R., Górski B., Ryncarz T.: Hybrydowe sorpcyjno-sprężarkowe systemy ziębnicze. Część 3. Wyniki badań systemu. Technika Chłodnicza i Klimatyzacyjna, tom nr 8 (2012), s. 322-331.

[5] Grzebielec A.: Możliwość zastosowania pomp ciepła w procesach suszenia. Chłodnictwo 8 (2013), s 18-20.

[6] Grzebielec A., Pluta Z., Ruciński A., Rusowicz A.: Czynniki chłodnicze i nośniki energii. Oficyna Wydawnicza Politechniki Warszawskiej, Warszawa 2011.

[7] Grzebielec A., Rusowicz A.: Kierunki rozwoju syntetycznych czynników chłodniczych w Europie, Polska Energetyka Słoneczna 1-4/2012, s.45-49.

[8] Grzebielec A., Rusowicz A., Kuta A.: Rola urządzeń i instalacji realizujących obiegi lewobieżne w wirtualnych elektrowniach. Rynek Energii 1 (110), 2014, strony 40-45.

[9] Jaworski M.: Thermal performance of heat spreader for electronics cooling with incorporated phase change material, Applied Thermal Engineering, 35 (2012) 212-219.

[10] Kavanaugh S.P.: Simulation an experimental verification of a vertical ground-coupled heat pump system. Ph.D. thesis. Oklahoma State University, Stillwater, OK, 1985.

[11] Kavanaugh S.P., Rafferty K.: Ground-source heat pumps-Design of geothermal systems for commercial and institutional buildings. ASHRAE, Atlanta, 1997. 
[12] Lorenc H.: Atlas Klimatu Polski. Instytut Meteorologii i Gospodarki Wodnej, Warszawa 2005.

[13] Trela M., Kwidzyński R., Butrymowicz D.: A study of transcritical carbon dioxide cycles with heat regeneration. Archives of thermodynamics, Vol. 34(2013), No. 3, 197-217.

\section{GROUND HEAT PUMP IN AIR CONDITIONING SYSTEMS}

\section{S u m m a r y}

Heat pumps, working with ground heat exchangers are devices characterized by some of the higher rates of efficiency. Better results attained, only in the case of devices with the ground water. The worst heat pumps, from the point of view of energy efficiency are solutions using atmospheric air as a heat source. Nevertheless, from the point of view of economics are far from coal or gas boilers. The main problem is the cost of the investment. Heating systems with heat pumps are the investment costs of a few to several times higher than others. The aim of the study is to determine how to improve the economic aspect of heat pumps work by using them in air conditioning systems during the summer. In order to model the work of the ASHRAE model was used for the vertical ground heat exchangers for Polish weather conditions. The results of the work show that the existing installation of the heat pump can be used as air-conditioning, and in addition, can significantly improve the efficiency of air conditioning systems (25\%). This is due to the fact that in such embodiments the upper heat source, in air conditioning systems and the source is not the atmospheric air. Ground in the summer is characterized by a lower temperature than the ambient air. All these factors make the economic balance of heat pump systems is getting more favorable. However, to achieve the best possible solution, with the cooperation of the heating system air conditioning system has already taken into account at the design of the building.

Keywords: heat pumps, ground heat exchangers, air conditioning, energy efficiency, mathematical modeling

Przestano do redakcji: $18.02 .2015 \mathrm{r}$.

Przyjęto do druku: 22.06.2015 r.

DOI:10.7862/rb.2015.41 